\title{
TEXTOS Y PARATEXTOS DE LAS POETAS RECOGIDAS EN LA REVISTA VERBO (1946-1963)*
}

\author{
XELO CANDEL VILA
}

Universitat de València macanvi@uv.es

RESUMEN: En este trabajo se analizan los poemas y las colaboraciones críticas de las poetas mujeres que participaron en la revista Verbo desde 1946 hasta 1963 para constatar que, pese al contexto ideológico y político hostil que no les permitía legitimar su voz ni como mujeres ni como escritoras, al menos en esta revista tuvieron una representación digna de ser mencionada. PALABRAS CLAVE: poesía, siglo XX, revista de posguerra, Verbo, mujeres poetas.

* Este artículo se halla vinculado al Proyecto de Investigación del Plan Estatal "Poéticas del 50: proyecciones y diversificaciones”, ref. FFI2013-41321-P (AEI/FEDER, UE). 


\section{WOMEN POETS' TEXTS AND PARATEXTS IN VERBO MAGA- ZINE (1946-1963)}

ABSTRACT: This essay analyses women poets' poems and critical contributions published in the journal Verbo from 1946 to 1963. Despite the hostile political and ideological context that hindered their legitimacy as women and as writers, in this journal, they were granted significance enough to merit an overview.

KEYWORDS: poetry, 20th century, post civil war magazine, Verbo, women poets.

$\mathrm{E}_{\mathrm{c} \text { nas }}$ un trabajo anterior, ya me dediqué a la revista Verbo (1946-1963), concretamente al papel que José Albi, uno de sus fundadores, había desarrollado como poeta y crítico en ella (Candel Vila: 2016). En aquella ocasión señalé el enorme interés de una revista hecha por dos entusiastas jóvenes valencianos que, a mediados de los años cuarenta, decidieron llevar adelante un proyecto que iría aumentando sus logros hasta llegar a consolidarse como una de las publicaciones señeras de esos años. Sin embargo, la revista no alcanzó ni mucho menos el reconocimiento nacional que tuvieron otras como Garcilaso, Espadaña, Cántico, Caracola, La caña gris o Papeles de Son Armadans. Tal vez ese desconocimiento es debido, por una parte, al hecho de que la revista original nunca ha sido reeditada como ha ocurrido en el caso de otras publicaciones rescatadas progresivamente del olvido y, por otra, sin duda, al talante más provinciano y menos ambicioso de la revista valenciana, reducida al menos en sus inicios a círculos locales y poco académicos. ${ }^{1}$ Efectivamente, si acudimos al sumario de los

${ }^{1}$ Quisiera expresar tanto al Centre Documental Casa Joan Fuster de Sueca (Valencia) como a los hijos del poeta José Albi mi agradecimiento por la colaboración prestada para poder consultar la revista Verbo (Alicante, ed. Verbo). Todos los números se encuentran encuadernados en cuatro volúmenes por voluntad de los dos directores: el primero recoge los primeros ocho números; el segundo volumen reúne los números del 9 al 20; el tercero, del 21 al 27 y el cuatro, del 28 al 33. Pese a que los trece primeros números no aparecen numerados, sino simplemente con la referencia del mes y primeros números, vemos que es sustancialmente más breve que el de los números siguientes, tal vez porque la publicación apareció al inicio con una ambición más bien modesta que irá aumentando a medida que la revista alcance mayor relieve. Esto se nota en que los dos primeros números de la revista, fechados respectivamente en marzo de 1946 y en abril-mayo de 1946, aparecieron con el título Cuadernos Literarios y es sólo a partir del tercero cuando la revista empieza a llamarse Verbo. Cuadernos Literarios. El último número de la revista es el 33, publicado en julio-septiembre de 1963. Los diecisiete años de existencia de la revista son decisivos en el panorama poético español, pues de 1946 a 1963 se produce el despegue hacia una poesía desligada de los imperativos nacionalcatólicos de la inmediata posguerra, tiene lugar el paso del "expresionismo tremendista a la poesía social”, en palabras de Ángel Luis Prieto de Paula (1993: 21), y la posterior eclosión de los poetas de medio siglo. Son los años también en los que asistimos a un lento reconocimiento en la esfera pública de la poesía de autoría femenina, desde la cerrazón inicial de los años cuarenta hasta el tímido afianzamiento de sus voces a finales de los años cincuenta y principios de los sesenta, pese a que, todo hay que decirlo, nunca alcanzaran el eco de sus compañeros hombres. La descripción de la revista merece sin lugar a dudas un trabajo aparte debido a la enorme cantidad de poetas antologados, a los debates abiertos sobre el panorama poético de medio siglo, a las traducciones y a las aproximaciones críticas que se recopilaron a lo largo de su trayectoria. No es el momento ahora, pero sí quisiera, al menos para que se vea el alcance de la revista, señalar que la nómina de poetas recogidos a lo largo de sus 33 números de existencia supera con creces los doscientos y de este número el dedicado a mujeres poetas, aunque no es tan cuantioso, sí resulta lo suficientemente relevante como para que consideremos el hecho de poder dedicar ahora un espacio a ellas.

El escenario social de los años cuarenta no era propicio a legitimación de las mujeres escritoras, sus derechos habían quedado mermados con la educación franquista que les negaba la posibilidad de que su discurso tu-

año de publicación, en este trabajo haré referencia a todos ellos con la numeración cronológica correspondiente seguida entre paréntesis del mes y año de publicación para evitar confusiones.

UNED. REI, 5 (2017), pp. 71-92

ISSN 2340-9029 
viera el mismo peso que el de sus colegas hombres. Como recuerda Jurado Morales, uno de los hechos que ayuda a entender esa nueva identidad de lo femenino amparada por la oficialidad franquista fue el decreto, fechado el 23 de septiembre de 1936, que prohibía la coeducación en España y que se acrecentó "en los nuevos estatutos y discursos de la Sección Femenina de Falange en los que se insiste una y otra vez en la subordinación y la inferioridad de la mujer con respecto al hombre como misión encomendada por la Patria" (2014: 529). Sin embargo, pese a ese contexto ideológico y social tan poco propicio, resulta patente el interés de los directores de la revista Verbo por publicar a poetas mujeres, ya que desde el primer número (marzo, 1946), a pesar de la brevedad del mismo, dos de los diez poetas que aparecen en el sumario son mujeres: Ana María Giner con el poema "Pensamientos" y María Ernestina Martín con dos breves poemas, "Ya no eres el de ayer" y "Un verso". Bien es cierto que ninguno de los tres poemas supone un gran reto poético y adolecen de un tono excesivamente tópico, rimas previsibles y temas recurrentes; el primero de ellos recuperando el tema del mañana que nunca llega, con cierto acento machadiano, el segundo sobre el desamor y el último sobre el valor del verso como ensoñación y determinación vital, con un palpable aliento becqueriano. Este interés inicial por editar voces femeninas se corrobora en el segundo número de la revista (abril-mayo, 1946), donde aparece, siguiendo la pauta de la publicación de presentar pequeños florilegios de algunos autores, ${ }^{2}$ la primera

${ }^{2}$ Además de la enorme representación de poemas independientes, observamos una tendencia a homenajear a algunos autores con breves antologías, que en muchos casos van acompañadas de una nota biobibliográfica. Es el caso de Carlos Talamás, con los poemas "Voz de siempre", "Epístola irremediable", "Madrigal", "Versos de la exaltación", "Yugo", "Plenitud” y "Mujer, crepúsculo" n. 10 (febrero, 1948); de Manuel Pinillos con "Motivo", "Soneto ante un retrato", "A un nuevo amor", "Dime", "Presencia", "Reiteración de la amada ausente", "Retorno a Dios" n. 11 (abril-mayo, 1948); de Gonzalo Sobejano con "Al fuego", "Muchacha en oración", "Nocturno", "Deseo", "Silencio de la tierra", "La ola", "Al encuentro" n. 13 (noviembre-diciembre, 1948); de los nueve poemas de Cantos íberos de Gabriel Celaya, n. 29 (diciembre, 1954); de una breve antología de la poesía alicantina contemporánea formada por Miguel Hernández, Carlos Fenoll y Ramón Sijé, n. 30 (abril, 1956); de una representación antológica de la joven poesía femenina de México, como veremos, con Margarita Paz Paredes, Dolores Castro, Rosario Castellanos, Enriqueta Ochoa o Gloria Riestra, n. 31 (primavera, 1958); y de una antología de Carlos Salomón en la que encontramos muestra antológica de poetas mujeres bajo el epígrafe "Poesía femenina" con dos poemas de Ma Ernestina Martín, "Primavera" y "Unión absoluta", que siguen la línea de una poesía amorosa como anhelo de refugio ante el mundo pero de escasa calidad; uno de María de Sales titulado "Viviré para el recuerdo" y otro de Anna M ${ }^{a}$ Giner titulado "Poema". Llaman la atención dos aspectos: por una parte, el hecho de que las mujeres aparezcan dentro de un apartado dedicado exclusivamente a la poesía femenina, es decir, por oposición a los poetas hombres y, por otra, el hecho de que tanto el tono como la temática de los poemas no respondan a las expectativas creadas por los coetáneos hombres. Se trata en todos estos casos de una poesía que en nada responde al registro poético propio de la época y que sigue respondiendo al modelo más o menos previsible de expresión de la intimidad dentro de las voces de mujeres. María José Porro apuntaba que "(f) ue habitual entre la crítica contemporánea considerar que el intimismo, la cotidianidad, la inspiración juanramoniana o machadiana eran notas específicas de una poesía menor cultivada casi exclusivamente por mujeres" (2013: 222).

A partir del n. 4 (octubrenoviembre, 1946) se comienza a reseñar de manera intermitente a poetas internacionales, en especial a poetas latinoamericanas, debido muy probablemente al contacto que Joan Fuster tenía con Cintio Vitier. Se inaugura así en la revista la sección "Poesía Americana" con la presentación en España de la poeta chilena Stella Corvalán (1913), quien hasta la fecha había publicado Sombra en el aire (Ateneo, Buenos Aires, 1940) y Palabras (Imp. Universitaria, Santiago, 1943), de quien se publica ahora el poema "Canto al mar", y con dos poemas, "Pastoral" y "Me ha besado en las manos", de la poeta de Costa Rica Myriam Francis. Del mismo número es la primera colaboración de Carmen Conde con "Los adolescentes de Orihuela". Este mismo apartado de "Poesía Americana” continúa en el n. 5 (diciembre, 1946), donde se recogen dos nuevos poemas de la poeta cubana Gloria Castañeda, "Vengo" y "Puente". Junto a ésta encontramos de nuevo la colaboración de Carmen Conde con el poema "Desierto Sajara" - perteneciente al libro Mi fin en el viento (1947) - y

los poemas "El camino", "La sed", "Soledad III", "Poema I", "Poema V", "La Historia, I", "El camino", "El secreto I", "El secreto II", n. 32 (eneromarzo, 1963).

UNED. REI, 5 (2017), pp. 71-92

ISSN 2340-9029 
se inauguran $\mathrm{M}^{\mathrm{a}}$ Esperanza Marina Buendía con el poema "A la Inmaculada Concepción” y Ma Ernestina Martin con "Carta lírica a José Albi en recuerdo de otra Navidad".

Los nombres de las colaboradoras en estos primeros números de la revista parecen repetirse. Por ejemplo, en el n. 7 (extraordinario de primavera) encontramos a la poeta catalana $M^{a}$ Marcela Sánchez Coquillat con el poema "Jardín íntimo" y de nuevo a la poeta chilena Stella Corvalán con "Preludio de la patria". Y en el n. 8 (julioagosto, 1947), además de a la poeta cubana Gloria Castañeda, que ya había sido recogida en el n. 5, esta vez con un poema de corte más convencional titulado "Pensando en ti”, de nuevo otra vez aparecen tanto Ma Marcela Sanchez Coquillat con el poema "Semana Santa vegetal" como Stella Corvalán con el poema "El viento y la muerte". Precisamente, de la poeta chilena se vuelve a hablar en el n. 13 (noviembrediciembre, 1948), dentro del apartado "Señal de libros", donde hallamos una reseña de su libro de poemas, Alma, (Valencia, 1948), compuesto por 32 poemas. La reseña crítica va firmada por las iniciales C.T.L y el tono empleado en ella no difiere del usado para hablar de otros libros de la época escritos por mujeres, insistiendo más bien en aspectos convencionales como la delicadez o la frescura a través de poemas en los que palpita "una sensibilidad intensamente lírica y una intuición genuinamente femenina". Estos aspectos, sin duda matizables, continúan forjando una imagen de la mujer encerrada en los temas más íntimos y estereotipados: "Amor, serenidad, melancolía y gozo, trenzan en este libro la selva idílica de los sentimientos. La poetisa se expresa con versos que abren una puerta luminosa a su espíritu”. Lo más grave es que se continúa indagando no en la calidad de los versos sino en la parte más personal y convencional de lo que debe ser lo femenino: "Los temas son los de la eterna poesía, y aunque el libro no descubre ningún horizonte inédito, tiene la gracia y la frescura de una delicada artesanía florecida entre los dedos enamorados de una mujer".

A partir del n. 9 (octubre-noviembre, 1947) encontramos mayor afluencia y sobre todo mayor variedad en los nombres de las poetas mujeres. La revista empieza a abrirse a las poetas más relevantes de estos años, aquellas que empiezan a ser conocidas a nivel nacional o a aquellas que mantuvieron una biografía llena de particularidades. Este último caso es el de Trina Mercader, poeta nacida en Torrevieja (Alicante) en 1919 aunque exiliada a Marruecos en 1940, donde fundó la revista Almotamid. De ella se publica ahora el poema reivindicativo "Oculto anhelo" en el que predomina la función apelativa a un "vosotros", a los otros que ignoran la verdad de una voz que representa a la de tantas mujeres silenciadas durante la posguerra: "No lo sabréis. He dado siete vueltas a la verdad/para borrar este duro silencio delator que me rodea". La poeta se sitúa en medio de una duda, escoger entre la rabia y la acción o la pasividad y la contemplación asumiendo el papel que la sociedad le otorga: “¡Tranquilizaos! Quiero vivir/ dulcemente enterrada, con vosotros, sin la orilla sedienta/ que me resume toda en esta luz de arcángel". Al final, sin embargo, la poeta asume su rol de pasividad, de madre generosa: "Quiero ser vuestra, sí. Quiero ser sólo madre./ Oh mujer. Mujer sólo, sin reverso ni orilla./ Y amaros en silencio, dulce o pasivamente./ He de negarme, sí. No lo sabréis. Lo juro”. Sonia Fernández, en un trabajo sobre la autora, decía que tomar conciencia del otro

no elude el desconcierto de su irrupción, lo propicia y genera el problema de la identidad y la diferencia: la unidad de la identidad, esto es, la cuestión de lo mismo y el conflicto o contradicción de la diferencia, aquella que posibilita el poder hacer diferencia para poder reencontrar la identidad, la que se expresa como alteridad en la que la memoria y el discurso no pueden quedar indiferentes (2006: 24).

De la poeta onubense María Luisa Muñoz de Buendía (1898) aparece en el n. 10 (febrero, 1948) una pequeña selección que responde a poemas breves de factura muy tradicional, casi con vocación de canción popular en torno a las penas de amor, que perpetúan la imagen de la joven mujer enamorada esperando inútilmente al amado que no llega: "Sardinas", "De plata y nieve", "No fue la luna", "Invierno" y "Nubecillas blancas", de clara huella juanramoniana. Llama la atención este tono tan tradicional y anacrónico para estos años viniendo de una mujer que había adquirido, gracias al poder adquisitivo de su familia, una alta formación intelectual en Inglaterra y cuyo primer libro Bosque sin salida fue prologado por Juan 
Ramón Jiménez, al que le unió una enorme amistad ${ }^{3}$. Otro poema que se recoge en el mismo número es "Alma gris" de María Ontiveros, formado por cinco estrofas de seis versos endecasílabos. En él hallamos de nuevo a un sujeto que expresa sus sentimientos mediante una serie de tópicos románticos como la identificación del yo con la naturaleza "siento en mí la tristeza del paisaje" o la indiferencia del amado ante la visión idealizada: "Oh, tú que pasas sin saber siquiera/ mi nombre, mi ambición ni mi quimera,/ acércate un instante".

En líneas generales, la poesía escrita por mujeres no escapa en los años cuarenta al modelo de sociedad patriarcal diseñado por el nacionalcatolicismo manteniendo en los poemas una imagen femenina que responde a estereotipos sociales de sumisión amorosa, de delicadeza, de feminidad o de espera pasiva ante la llegada del amado. Como apunta José Jurado Morales,

la mujer teje su identidad en función de los otros, especialmente de los varones de la casa (padre, marido, hijo), es decir, edifica su identidad a partir de la alteridad, no de la mismidad, lo que puede repercutir en un estado de frustración y un sentimiento de irrealización vital (2014: 527).

Es especialmente llamativo el retroceso de algunas poetas mujeres de posguerra aquí representadas con respecto a los grandes hallazgos de las modernas mujeres de la República (Mangini, 2001) que habían incluido en los programas el principio de igualdad jurídica y que en su juventud habían gozado de una libertad económica y legal sin parangón.

A finales de los años cuarenta, especialmente a partir del n. 11 (abril-mayo, 1948), empezamos a comprobar que la revista incorpora de manera más natural a poetas mujeres que se atreven a presentar ya en sus poemas una voz disidente con el momento en el que les ha tocado escribir, conscientes de que la época franquista supuso un claro retroceso en sus derechos y que diseñan un claro punto de rebeldía con respecto a la imagen más tradicional que se tiene de ellas. Es el caso de Concha Zardoya, con

${ }^{3}$ Véanse las palabras que de dedicó Juan Ramón Jiménez: http://www.uhu.es/biblioteca/labuhardilla/wp-content/uploads/2015/09/MLUISA249.jpg

UNED. REI, 5 (2017), pp. 71-92 el poema "Las manos del espejo" - dedicado precisamente a Pablo Neruda, del libro inédito entonces Las manos y los pájaros-, quien en el n. 15 (marzo-abril, 1949) publica el poema "La escalera del tiempo voy subiendo" y en el n. 16 (mayo-julio, 1949) el poema "Las ciudades (Toledo)". Cabe destacar que en la revista se reseñaron también algunos trabajos suyos. Por ejemplo, en el n. 21 (febrero, 1951) Joan Fuster comenta su trabajo Eugene O’Neill, a la luz del expresionismo — publicado en México en 1949 y recogido posteriormente por la editorial Edhasa en Verdad, Belleza y expresión en 1966- y en el n. 26 (julio, 1952) se reseña La hermosura sencilla, (Hispanic Institute in the United States, 1953) resaltando sobre todo su "voz llena de transparencias, de una leve riqueza esencialmente lírica", sin hacer alusión en ningún momento a su condición de género. Es también el caso de Ángela Figuera Aymerich, quien publica el conjunto "El fruto redondo" con cinco breves poemas que aparecerán en su primer libro Mujer de barro (1948) aunque no en el mismo orden ni con los mismos títulos. Así, por ejemplo, el poema "Poesía pura" es el que después pasará a llamarse propiamente "El fruto redondo" por la poética que encierra; frente a la poesía pura ella prefiere esos versos que "nacen redondos como frutos/envueltos en la pulpa caliente de mi carne"; de los otros se conservan "Pereza" y “Otoño", mientras que desaparecen del libro "Dormir" y "Preguntando". De este libro se hará una crítica en el n. 12 (julio-agosto, 1948) en el habitual apartado de reseñas titulado "Señal de libros" junto con otros autores que publicaron libros en 1947 o 1948 como Manuel Pinillos (A la puerta del hombre, 1948), Rafael Múgica (La soledad cerrada, 1947), E. Gutiérrez Albelo (Cristo de Tacoronte, 1947) o Pablo García Baena (Mientras cantan los pájaros, 1948). ${ }^{4}$ La crítica que se le hace, firmada bajo las siglas J.V., ado-

${ }^{4}$ En este n. 12 se recoge una encuesta titulada "Posiciones y puntos de vista" para determinar cuál es el mejor libro de poesía publicado en 1947 en España. El libro más favorecido es Los muertos de José Luis Hidalgo con diez opiniones favorables; le sigue Más allá de las ruinas de Germán Bleiberg, con tres opiniones favorables, y empatan con una opinión favorable cada uno los libros Alegría (Premio Adonais de ese año) de José Hierro y Mujer sin Edén de Carmen Conde. Leopoldo de Luis ofrece su opinión sobre los mejores libros de 1947 publicados en España y entre ellos destacan cuatro escritos por mujeres: Mujer sin Edén de Carmen Conde, Dominio del llanto de Concha Zardoya, Todavía la vida de Aldecoa y Sea la luz de Carmen Conde.

UNED. REI, 5 (2017), pp. 71-92

ISSN 2340-9029 
lece todavía de una imagen excesivamente convencional y estereotipada de lo que se entendía que debía ser la poesía escrita por mujeres:

Es este un libro de versos que sólo pudo haberlos escrito una mujer. Una sensibilidad tan plenamente femenina y a la vez tan íntegra y tan cálidamente humana, que llega a la Poesía con la misma sencillez con que hasta ella llega la vida sin concesiones de ninguna clase a cualquier norma o cualquier estética.

Esto llama especialmente la atención en 1948 si atendemos a que en esa época era muy palpable la influencia inexcusable de Dámaso y Aleixandre con sus respectivos Hijos de la ira y Sombra del paraíso, la de la revista Espadaña, en la que Figuera aparece hasta en veinte ocasiones, así como la de los primeros libros de los poetas sociales, por lo que ya se respiraba en el ambiente el giro a una poesía de signo comprometido. La crítica continúa haciendo hincapié en el reducido círculo poético de Figuera, limitado al hogar y la vida familiar, aunque se apuesta por su poderoso temperamento lírico, capaz de romper estos límites y salir hacia otros problemas más sociales de la poesía contemporánea. Esta concepción sobre su poesía va a ir cambiando a medida que se vayan reseñando sus siguientes libros; por ejemplo, en el n. 26 (julio, 1952), pese a la inicial comparación de Soria pura (1949) con Machado, pronto se dice que nada tienen que ver sus versos con los del sevillano ya que presenta "un impresionismo sin complejidades, una sensibilidad siempre al borde del grito, todo vertido en un lenguaje directo, claro, a tono con la inmediatez de las experiencias que canta”. Sin embargo, a medida que la crítica avanza encontramos de nuevo esa mirada de género: "siente una femenina ansia de entrega que, en poemas como 'Baño, 'Río' o 'Cañaveral' alcanza un relieve poderoso”. Otros libros de Figuera fueron también reseñados en Verbo, como ocurrió con Víspera de la vida (Madrid, Colección Nebli, 1953), en el n. 28 (diciembre, 1953). Aunque la reseña no está firmada, se señala la distancia entre los primeros libros de Figuera y este nuevo: "El encanto vivo y sensual de sus primeros versos se ha convertido en esta ardiente llamarada de densidad y fortaleza. Todo en ella se nos ofrece grávido, pleno, sin resquicios, a través de su voz recia, hiriente, entre perentoria e imprecativa". Se señala en ella una tensión inacabable llena de humanidad y de sinceridad "que nos hace llegar la verdad con una tal carga de realismo poético, que a veces nos abruma”. Esta concepción de su poesía más cercana al realismo es la que empieza a consolidarse cuando en el n. 29 (diciembre, 1954) Manuel Molina, en el apartado "Cuatro poetas de hoy", habla sobre Celaya, Blas de Otero, Ángel Crespo y Ángela Figuera Aymerich. Como recuerda, aunque la poeta ya había publicado Soria pura y Mujer de barro, el conocimiento de la poeta llegó a Verbo con Vencida por el ángel, con el que obtuvo el premio en el concurso de la revista convocado en 1950. De estos poemas destaca especialmente su "contenido sustancial, denso y vigoroso" que opera en las almas más sensibles: "duelen estos poemas de amor, de desesperación y de ternura infinita”. Años después fue galardonada con el premio de la "Colección Ifach" por El grito inútil, libro del que Molina destaca que "es un grito de impotencia, de derrota, de desesperación última; una llamada al vacío de la soledad sin remedio”. Eso sí, Molina continúa remarcando su condición de género, es decir, resaltando sus cualidades en comparación únicamente con otras mujeres poetas: "ninguna mujer poeta, que yo sepa, aborda tan brava, tan crudamente, el tema de la guerra y sus consecuencias catastróficas para la humanidad civilizada". La poeta toledana Mercedes Chamorro (1925) aparece también representada en el n. 13 (noviembrediciembre, 1948) con una selección de poemas - "Primavera", "Florecer", "Regreso al amor", “Tú me sabías", "Es abril y estoy sola”, "La estatua” y "Presencia del hombre" - que al año siguiente compondrán su libro Primavera, publicado precisamente por Verbo. ${ }^{5}$ Aparece una brevísima nota biográfica donde solo se dice que nació en Toledo en 1925 y que en 1945 publicó en Madrid su primer libro de poemas, Ramo de romeros. Aparte de este libro, únicamente había aparecido en algunas revistas, por lo que se presupone que esta selección de versos es una apuesta por la entonces joven Mercedes Chamorro, de quien en el n. 12 ya se había publicado el poema "Mis manos". De estos nuevos poemas antologados se destaca en

${ }^{5}$ Mercedes Chamorro comenta en la antología de Conde: "Yo sentí la inclinación a la poesía desde muy pequeña. Los primeros versos los escribí a eso de los trece años. Por fin, en 1945, publiqué en Madrid mi primer libro, Ramo de romeros, que recogió toda mi obra adolescente. Y en 1949 publicó la colección 'Verbo', de Alicante, Primavera, un pequeño cuaderno que tuvo mucha aceptación de público" (Conde, 1954: 103).

UNED. REI, 5 (2017), pp. 71-92

ISSN 2340-9029 
especial la sensibilidad del tono poético, dado que es el amor el centro de la inspiración poética, pero aun así

hay que situarla en el ribazo sereno donde el lenguaje y la idea florecen hermanadas con perfecto equilibrio. Equilibrio sí, pero ímpetu también. Ímpetu joven que quiere decir luz, aire, aurora, pero su propia hondura poética le devuelve a veces otros ecos: Dolor, Hombre, Tiempo. ${ }^{6}$

Llama la atención que en la nota que acompaña a la autora se diga que su voz clara y vital sacude las nieblas de nuestro espíritu "demasiado saturado de humanidad dolida y de angustiosos presentimientos". Para María Payeras, su propia sexualidad, conflictiva en la media en que su verbalización se opone a las imposiciones culturales heredadas, es un tema importante que aparece en Primavera, libro en el que

la mujer parece haber conseguido despojarse de los prejuicios morales. La aceptación de su faceta sensual, la expresión del erotismo, tienen en ella, por lo general, un carácter jubiloso, en tanto que celebran a vida y la afirmación en la propia identidad (Payeras Grau, 2009: 181).

Del mismo modo, otras poetas conocidas como María Beneyto son antologadas en la publicación. Aparte del poema "Confesión de noche", que aparece en el n. 29 (diciembre, 1954) con una ilustración a cargo de Melchor Aracil, encontramos en el n. 32 (enero-marzo, 1963) los poemas "Duro tiempo", "Con el mar" y "Mi padre" con una nota en la que se apunta que la suya es quizás la mejor voz femenina de la generación actual. Y ello es en parte porque nace de un inicial impulso estético que va desembocando, como se indica, en la miserable realidad de los hombres. Sin embargo, todavía no se apunta a la dimensión social de su poesía, sino más bien a una dimensión de pureza estremecedora y una claridad para decir las cosas, para convertirlas en materia poética: "María Beneyto es dueña de una de las más maravillosas, claras, hondas, apasionadas y finí-

${ }^{6}$ Esta misma nota, firmada por José Albi, es la que aparecerá en el apartado "Señal de libros" del n. 15 (marzo-abril, 1949) cuando se reseñe precisamente la aparición del libro Primavera en ediciones Verbo. simas sensibilidades de nuestra poesía contemporánea”. Además, encontramos también en el mismo número tres fichas poéticas correspondientes a tres libros de María Beneyto. Del primero de ellos, Eva en el tiempo (1952), se dice que es un libro sencillo y hondo como son los de la autora, en el que se desprende una armonía tras la que se esconde el asombro y la ternura por todo lo que sufre "por todo lo impuro, lo desterrado, lo sombrío. Hay en ello una radical actitud femenina, suave y humilde pero llena de fuerza, de decisión e incluso de potencia trágica”. De Tierra viva (1956) se destaca más una faceta poética y humana que tiende a lo bello, a la alegría, a la luz, pero que se solidariza de manera casi maternal con el sufrimiento de los que le rodean y ello es porque sabe del dolor y en todo "pone su ternura y su enorme capacidad de amor; y ahonda buscando, por detrás de la realidad inmediata, una razón trascendente". De Poemas de la ciudad (1956) se apunta que es el libro que tal vez objetiva de un modo más inmediato, más directo, su preocupación social, ya que está menos vinculado a los estados anímicos: "Duele la ciudad y duele su abandono y su desesperanza; se vislumbra, se palpa un halo de ternura, pero la visión, en general, es algo más seca que en libros anteriores".

El interés por seguir dando muestras de poetas americanas sigue en el n. 12, donde hallamos un romance tradicional de la argentina Rosita Stella Elizondo Córdova titulado "Baila mi moreno", y en el n. 13 (noviembre-diciembre, 1948) con dos poemas de la uruguaya Orfila Bardesio Vila, "Danza en el viento" y "Esclavitud", que van acompañados de una nota en la que se resalta la juventud y originalidad de la poeta, su "apasionada intuición de la vida, que parece haber heredado algo de la potencialidad magnífica de Delmira”. De nuevo, en el apartado “Señal de libros” del n. 14 (enero-febrero, 1949), aparece la reseña del libro Fuga (Barcelona, Colección Ariel) de la puertorriqueña Ana Inés Bonnin Armstrong, de quien se nos dice que la suya es una poesía "no filiada a ninguna escuela, correcta, atildada, con una vena cálida y tumultuosa de soterrado lirismo". Parece, pues, una poesía serena que fluye sin sobresaltos, ceñida a los temas eternos, en la que destaca "la elegancia pulcra y preciosa de un alma elemental y apasionada. Elegancia en el decir lacónico y exacto". De la misma sección es la reseña al libro de Carmen Conde Cartas a Katherine Mans- 
field $^{7}$ (Zaragoza, Doncel) publicado en 1948, en la que se hace hincapié en que es precisamente en el género epistolar donde más precisas muestras literarias nos han prodigado las mujeres. En este mismo número aparecen también las primeras colaboraciones de María Beneyto, con el poema "Santiago de Compostela", y Ángeles Escrivá con los poemas "Alamedas en noviembre" y "La mañana", del libro entonces en preparación Canciones de tiempo bueno. En el n. 18, (agosto-septiembre, 1950), se ocupan de la poeta hondureña Ada María Navas (Juticalpa, 1908) y de su único poemario publicado, Sin amarras (Tegucigalpa, 1937). Es significativo que se reseñe la única obra de una autora hondureña pese a que su opinión sobre ella no resulta muy favorable, puesto que se la acusa de estar desconectada de la espléndida tradición de la lírica femenina hispanoamericana, quedando más bien "en los límites palabreros y musicaloides del modernismo, del peor modernismo el de Villaespesa o el de la 'monja laica' que fue Amado Nervo", aunque reconocen que tiene algunos aciertos apreciables. De la poeta cubana Fina García Marruz ${ }^{8}$ Joan Fuster reseña en el n. 26 (julio, 1952) Las miradas perdidas (La Habana,1951). Se trata de una crítica un tanto convencional que de nuevo clasifica a la poeta por su género y se la contempla únicamente desde ese punto de vista, pues su primera sorpresa al leer el libro "ha sido el contraste que ofrece con el clisé fatigado por la poetisa en sus diversas variedades: la sensual, la sensiblera, la energúmena. Fina García Marruz no responde a ninguna de estas actitudes tópicas". Sin embargo, añade que su sensibilidad lírica no sólo es excepcional respecto

\footnotetext{
7 Sobre la poeta británica Katherine Mansfield se publican en el n.17 (octubre-diciembre, 1949) tres poemas: el primero, "El hombre de la pata de palo", escrito cuando la autora solo tenía trece años, y los otros dos, "Las voces del aire" y "El abismo", muy posteriores. En los tres poemas, traducidos por Matola Ramón, según indica la nota que acompaña a la autora, "reencontramos la misma irisada sencillez, la misma poesía dulce y viva que nos robaron el corazón en sus cuentos y narraciones". El mismo número recoge también un "Soneto" de la escritora estadounidense Edna Saint Vicent-Millay (traducido por Emilio Ballagas), quien había ganado el Premio Pulitzer de Poesía en 1923 por The Ballad of the Harp-Weaver.

${ }^{8}$ Recordemos que en el n. 17 (octubre-diciembre, 1949) Joan Fuster se encarga de reseñar la antología Diez poetas cubanos (1937-1947) de Cintio Vitier, entre los que
} se encuentra una única mujer: Fina García Marruz.

de la poesía femenina corriente de allá, sino que lo es en absoluto pues es "una sensibilidad avezada al ejercicio de la nostalgia y a la comunión sosegada con la lumbre de lo trascendente". Una nueva muestra antológica de poesía latinoamericana se produce en el n. 31 (primavera 1958) bajo el epígrafe "La joven poesía femenina de México", en la que se presenta un único poema de cinco jóvenes poetas con una breve nota biográfica cada una de ellas. De Margarita Paz Paredes se publica el poema "Solo yo" y se comenta que quizás sea la que mayor popularidad ha alcanzado entre las más jóvenes promociones literarias mexicanas. De ella se destaca su voz, eminentemente lírica, por la que fluye una "melancolía que se entremezcla a un impulso de gozo que brota de la tierra y de la carne - una carne dijérase espiritualizada, transida-". El poema de Dolores Castro es "Vino la hoz" y con él se ejemplifica una poesía que encierra un fondo de patetismo, la muerte queda por detrás de la tristeza, pero su expresión guarda tal finura, tal limpidez lírica "que transfigura y clarifica toda su carga de pasión y de dolorosos presentimientos". Otro carácter tiene la voz de Rosario Castellanos, de quien se publica el poema "A los danzantes de las ferias". De su poesía sobresale la serenidad y hondura, algo que viene de muy dentro, del alma y de los siglos de la tierra, poesía esencialmente indígena en la que se "agolpan en la sangre todas las resonancias ancestrales de su raza, que ella busca y halla en su propio dolor". La poesía de Enriqueta Ochoa, de quien se publica el poema "El río de tu vida", es en cambio más bien religiosa, "de apasionada búsqueda, se estremece en su propia reciedumbre, en la plenitud serena y a la vez violenta de una voz que sangra de amor y de alto empeño". Por último, el poema "Soledad", de Gloria Riestra, la poeta más joven de todas, cierra la antología. De ella se señala una pasión íntima, más bien contenida y rica en matices: "Una intensidad que no se vuelca de golpe, sino que parece irse diluyendo hasta agazaparse tras cada palabra, para mantener así una tensión constante, pero sutil y siempre armoniosa”.

Un apartado especial merecerían las colaboraciones de las escritoras como críticas literarias, en las que sin lugar a dudas presentan una postura más objetiva y menos condicionada por prejuicios estéticos que la de sus colegas hombres. En el número doble 19-20 (octubre-diciembre, 1950), dedicado al homenaje a Gerardo Diego, además del breve texto en prosa de Gabriela Mistral "Un poema”, dedicado al poema "El ciprés de 
Silos" y fechado en Madrid en julio de 1934, y de los poemas de Carmen Conde "En el homenaje a Gerardo Diego" y Ángela Figuera Aymerich "Ángeles de Gerardo", Concha Zardoya firma el ensayo "Historia de una insistencia temática: Castilla”. En él parte de los poemas de Diego en los que se refleja la impresión de Castilla que el poeta cántabro ha sentido y que la autora ve significativamente unidos a los de Antonio Machado pese a las diferencias de matiz entre ambos poetas. En su opinión, Machado es más pintor y más filósofo; Gerardo Diego, más dibujante y más conceptual. Pero no hay panteísmo en ninguno de los dos: "Ni el uno ni el otro se pierden en la Naturaleza, abrazándose a ella lánguidamente, entre perfumes y rumores". Machado le resulta más recio, sobrio e intenso; en cambio, Diego, más ecléctico, ágil y moderno: "El andaluz es más melancólico, pero más uniforme y constante. Diego es de aristas más fuertes y bien talladas, de aquí su polifacetismo lírico". Después de esa comparación entre ambos poetas, se centra en la evolución de la obra de Gerardo Diego, desde Soria (1923), concretamente en los poemas "Romance del Duero", "San Baudelio de Berlanga" y “Tejados de Soria”, pasando por Versos humanos (1925), en concreto con los poemas "El ciprés de Silos" y "Nuevo cuaderno de Soria", hasta llegar a Alondra de verdad (1943) para concluir que a lo largo de estos tres libros lo que al principio era una aproximación al secreto de Castilla, en el último libro citado se ha concretado y acendrado en versos y poemas de síntesis radiosa y trascendente. Todo culmina en una realidad plena y absoluta:

Castilla no es una entelequia ni una metáfora: es una realidad y una vivencia, un caudal de luz en eterna fluencia: es reino de vida y espíritu, el paisaje de más alta categoría estética y espiritual de toda España y quizá del mundo entero.

Otra de las autoras más prolíficas en cuanto a su participación como crítica en la revista valenciana fue María de Gracia Ifach, seudónimo de Josefina Escolano, que en el n. 22 (junio, 1951) firmó el trabajo "La poesía de José Hierro". Se queja la autora de la poca atención que se ha dedicado al poeta en la prensa y en las revistas literarias, por ello, tal vez "no diga todo lo que merece, pero se han ocupado tan poco de esta auténtica, humana y varonil poesía que cuanto quede anotado debe resultar interesante por sentido y sincero". María de Gracia Ifach hace un recorrido por la obra del poeta desde Tierra sin nosotros (Proel, 1947): "Del primero al último de sus poemas identifican al hombre que fue desde su adolescencia en lucha con un destino adverso, de cuyos obstáculos casi siempre salió victorioso". La suya es una crítica que ve constantes conexiones con la biografía del poeta: "José Hierro comenzó a ser poeta empujado por la fuerza de su hombría más que por una blanda y pasiva posición espiritual”. No en vano, considera Ifach que la sustancia principal de sus versos es precisamente la vida, así al hablar de su siguiente libro, Alegría (1947), concluye que la suya es una poesía llena de experiencias, de vivencias líricas, de recuerdos y presencias, añoranzas y recuperaciones. El último libro comentado, Con las piedras, con el viento (1950), es para ella el más pleno "por esencialmente amoroso, traza un zigzagueo de sinsabores y venturas que complican el alma del poeta transiéndola de amargura o inundándola de felicidad”. La misma autora en el n. 28 (diciembre 1953) es la encargada de realizar la crítica a cuatro libros de mujeres: La sangre, de Elena Quiroga; Fiesta al Noroeste, de Ana María Matute; La muerta, de Carmen Laforet y Nosotros, los Rivero, de Dolores Medio. De ellos comenta que han aparecido casi simultáneamente y que han servido para desempalagarse del gran número de poetas que se está generando desde la postguerra, fenómeno que no ocurre entre los prosistas. Justo un año más tarde, en el apartado "Crónicas” del n. 29 (diciembre, 1954), destaca una crítica de María de Gracia Ifach titulada "Antologías", en la que repasa algunas de las antologías de poesía más destacadas de esos años. Entre ellas, Poemas de Carmen Conde, publicada en Milán; la Antología Poética de José Hierro, Premio Nacional; Poetas españoles contemporáneos, de Roque Stefan Scarpa, en Santiago de Chile; Poèmes d'Espagne, traducidos por Noële y André Piot, en París: el Panorama de la poesía moderna española, de Enrique Azcoaga en Buenos Aires o la Antología de la poesía femenina viviente de Carmen Conde. Sin embargo, se detiene en otras dos: Antología biográfica de escritoras españolas de Isabel Calvo de Aguilar (Madrid, Biblioteca Nueva, 1954) y Antología de Adonais de José Luis Cano. El extenso volumen presentado por Isabel Calvo - son exactamente 891 páginas que recogen datos biográficos, fotografías y colaboraciones de 85 mujeres de letras- adolece, en palabras de María de Gracia Ifach, "de armonía o unidad cualitativa”. De hecho, el 
volumen presenta a las autoras por estricto orden alfabético sin contemplar distinciones de categorías o de calidad literaria, por lo que la antóloga se ha preocupado más "de ofrecer un documento informativo sobre casi todas las escritoras contemporáneas, que ya forman ejército en España, con más valor biográfico que literario". La antología no recupera únicamente a las autoras más conocidas, sino a un amplísimo mosaico de voces que aun así no representan para María de Gracia Ifach la totalidad de nombres, ni siquiera los más valiosos, pues en su opinión faltarían los de Eugenia Serrano, Pino Ojeda y Trina Mercader, entre otras escritoras conocidas, sin olvidar que tampoco aparece Elena Quiroga porque se negó a participar en la antología. Un aspecto me resulta significativo, sin embargo. Me refiero al hecho de que se compare siempre al colectivo de escritoras entre sí y no en contraste con el colectivo de escritores hombres: "a poco que se conozca el panorama literario femenino, se observa en este abundante grupo tan grandes diferencias que, en ciertos casos, resultan como antípodas entre sí, tan diametralmente opuestos se hallan sus escritos". La autora menciona también la diferente preparación intelectual de las colaboradoras y como consecuencia natural, son diversos también y aun opuestos sus modos de concebir la obra de creación. No da nombres, pero sí alude a la nimia calidad de algunos textos, "relatos sin posible salvación de puro cursis", aun a pesar de la heterogeneidad señala que es de agradecer la laboriosidad y el entusiasmo de la publicación. En cuanto a la antología de Cano en torno a la colección Adonais, comenta Ifach que con este volumen extraordinario se conmemora la salida número 100 de la colección y en él se recogen los sesenta poetas que publicaron en la colección madrileña desde 1943. En el orden de interés nuestro, entre esos poetas representados se reúnen poetas como Ernestina de Champurcín, Carmen Conde, Susana March, Concha Zardoya y Juana García Noreña, seudónimo de José García Nieto. De todos ellos se ofrece una nota biobibliográfica, dos poemas y una fotografía, exceptuando el caso de la poeta más joven. La idea de esta publicación fue de José Manuel Blecua y el valor del volumen crece exponencialmente con el prólogo de Vicente Aleixandre "y ensamblado con la historia, un resumen de la poesía hispánica en 1939 y su evolución hasta nuestros días". Pero la labor como crítica en la publicación valenciana de María de Gracia Ifach no acaba aquí. En el n. 30 (abril, 1956) comenta los "Últimos libros de Carmen Conde", es decir: Poesía femenina española viviente (Madrid, Arquero, 1954), Vivientes de los siglos (Madrid, Los Poetas, 1954) y Empezando la vida. Memorias de una infancia en Marruecos (1914-1920) (Tetuán, Intimad, 1955). Este último son sus recuerdos de niña, sus primeras reacciones ante la naturaleza, los animales, el mar, descritos de manera que dan "la impresión en muchos casos de que fuese la niña Carmen quien los describiera. Así son de tiernos, de sencillos y sinceros estos pequeños relatos del comienzo de su vida”. Comenta María de Gracia Ifach que con Vivientes de los siglos celebra Conde sus bodas de plata con la poesía, en este libro nos ofrece lo que "permanece en el espacio a través del tiempo, patrias y destierros del hombre mortal, eternizado en sus descendientes, es un libro que consolida la madurez humana y metafísica de la poeta pero sin ampliar su órbita poética”. Aunque, sin duda, mucho más importante para dar a conocer la obra de las mujeres escritoras fue la antología Poesía femenina española viviente (1954) al recuperar la voz de veintiséis mujeres. ${ }^{9}$ Este volumen fue ampliado con una segunda antología publicada en 1971 con el título Poesía femenina española (19501960), donde recoge a otras treinta y tres poetas nuevas. Ifach destaca que, a pesar de la diversidad de estéticas que hay entre las poetas antologadas, todas ellas son excelentes, aunque hace una mención especial a Celia Viñas. La antología reúne una lírica femenina actual que no es mimética ni imitadora del poeta hombre, "sino que tiene color, sentido propio, obedeciendo a la responsabilidad que cada poetisa tiene como mujer, ante su tiempo y el caos universal que lo integra”. Como indica Blas Sánchez Dueñas, inquieta comprobar que las primeras antologías de los años cincuenta carezcan de una representación femenina cuando algunas de las poetas de

${ }^{9}$ Como recuerda María José Porro Herrera (2013), anteriormente Ma Antonia Vidal había ya abierto el panorama en su libro Cien años de poesía femenina española e hispanoamericana (1943), pero fue la aportación de Conde la que mayor repercusión tuvo. Las poetas antologadas en ella fueron: María Alfaro, Ester de Andreis, María Beneyto, Ana Inés Bonnín, Carmen Conde, Mercedes Chamorro, Ernestina de Champurcín, Beatriz Domínguez, Ángela Figuera, Gloria Fuertes, Angelina Gatell, Clemencia Laborda, Chona Madera, Susana March, Trina Mercader, Pino Ojeda, Pilar Paz Pasamar, Luz Pozo, Josefina Romo, Alfonsa de la Torre, Josefina de la Torre, Montserrat Vayreda, Pilar Vázquez Cuesta, Pura Vázquez, Celia Viñas y Concha Zardoya.

UNED. REI, 5 (2017), pp. 71-92

ISSN 2340-9029 
este período "protagonizaron iniciativas importantes para este grupo poético y convivieron en las revistas, premios, actividades, lecturas, colecciones y demás actos que envolvieron la vida de este grupo hasta definirlo" (2013: 229-250). En las primeras recopilaciones generacionales no se incluía a ninguna mujer, como ocurrió con la de José Ángel Valente "Once poetas” de 1955; un año después, en 1956, Mariano Roldán solo recoge dos poemas de Pilar Paz Pasamar en su pequeña muestra antológica y Rafael Millán en Veinte poetas españoles (1955) únicamente incorpora el nombre de una mujer, Ángela Figuera. José Luis Cano recoge a ocho autoras en la segunda edición de Antología de la nueva poesía española (1963): Carmen Conde, Ángela Figuera, Concha Zardoya, Susana March, Gloria Fuertes, María Beneyto, María Elvira Lacaci y Nuria Parés. José María Castellet en Veinte años de poesía española (1959) también recupera a Ángela Figuera, Gloria Fuertes y María Beneyto. Mayor es la presencia femenina en la antología de Luis Jiménez Martos Nuevos poetas españoles (1961) pues, de los once poetas antologados, cuatro son mujeres: Gloria Fuertes, María Elvira Lacaci, Concha Lagos y Pilar Paz Pasamar. Deberíamos contar igualmente con la antología de Leopoldo de Luis Poesía social (1939-1964) de 1965 que reúne a Ángela Figuera, Gloria Fuertes, Ma Elvira Lacaci y María Beneyto. La última aparición de Carmen Conde en la revista fue precisamente en el n. 33 (julio-septiembre, 1963) con un poema reivindicativo titulado "Poemas". Destaca la nota que lo acompaña, pues de nuevo se insiste en compararla con la poesía escrita por mujeres y en valorarla en esa dirección restrictiva al indicar que la valiosa personalidad y la potencia creadora de Carmen Conde han abierto caminos a la poesía femenina contemporánea. Sin duda, se siguen manejando estereotipos a la hora de definir la poesía escrita por mujeres: "Carmen Conde ha borrado los últimos equívocos sobre la posible supeditación de la actitud creadora femenina a los mínimos ideales de una trivial sensiblería”.

En resumen, la revista Verbo estuvo atenta a cuantas manifestaciones estéticas y culturales surgieron durante los años en que estuvo vigente. En sus páginas hallamos no únicamente poemas, narraciones, ensayos y piezas teatrales sino también traducciones de autores extranjeros, crónicas europeas y americanas, pintura, reseñas de libros, revistas y publicaciones críticas tanto nacionales como internacionales, que nos ofrecen un panora- ma bastante completo y sobre todo sorprendente del arte y el pensamiento de los años cuarenta y cincuenta. De manera lógica, aunque sorteando las dificultades propiciadas por una sociedad patriarcal que no les permitía manifestarse de manera natural, los dos directores de la revista, José Albi y Joan Fuster, supieron que la voz de las mujeres debía ser escuchada y acogieron desde el primer número hasta el último una elevada representación de poetas mujeres. Si bien es cierto, como hemos comprobado, que todavía la mirada sobre sus libros adolece al inicio de ciertos componentes estereotipados y convencionales, también debemos señalar que lentamente se avanza hacia una mayor consideración de su voz. Las propias poetas fueron conscientes de esa restricción social y cultural a la que eran supeditadas, por ello clamaron desde sus poemas y desde sus trabajos críticos un lugar desde el que poder legitimar su discurso. No siempre fueron escuchadas de manera objetiva y dejando atrás prejuicios de género. Sabemos que no se las incluyó en el marco canónico generacional, pero publicaciones como Verbo constatan que su existencia fue real y, aunque no llegaran a ser protagonistas de un panorama poético reduccionista que las eliminó de la historiografía literaria, su firma está ahí para quien quiera comprobar la injusticia a la que han sido y siguen siendo sometidas.

Recibido: 8/5/2017

Aceptado: 5/6/2017

\section{Referencias bibliográficas}

Candel Vila, Xelo (2016): "El poeta José Albi en la revista Verbo (19461963)", en Fuera de foco. Aproximaciones a la diversidad poética de medio siglo, ed. de María Payeras Grau, Madrid: Visor, pp. 87-102.

Cano, José Luis (1963), Antología de la nueva poesía española, Madrid: Gredos.

Castellet, José María (1959), Veinte años de poesía española, Barcelona: Seix Barral. 
Conde, Carmen (1954), Poesía femenina española viviente, Madrid: Arquero.

--- (1967), Poesía femenina española (1950-1960), Barcelona: Bruguera.

Fernández Hoyos, Sonia (2006), Una estética de la alteridad. La obra de Trina Mercader, Madrid: UNED.

Jiménez Martos, Luis (1961), Nuevos poetas españoles, Madrid: Ágora.

Jurado Morales, José (2014), “El discurso patriarcal en la poesía femenina del primer franquismo", Revista Signa, 23, pp. 525-544.

Luis, Leopoldo de (1965), Antología de la poesía social (1939-1964), Madrid: Alfaguara.

Mangini, Shirley (2001), Las modernas de Madrid. Las grandes intelectuales españolas de vanguardias, Barcelona: Península.

Millán, Rafael (1955), Veinte poetas españoles, Madrid: Ágora.

Payeras Grau, María (2009), Espejos de palabra. La voz secreta de la mujer en la poesía española de posguerra (1939-1959), Madrid: UNED.

Porro Herrera, María José (2013), "Escritoras en los Cuadernos de Ágora", Desde las orillas. Poetas del 50 en los márgenes del canon, ed. de María Payeras Grau, Sevilla: Renacimiento, pp. 209-228.

Prieto de Paula, Ángel Luis (1993), Antología de poesía española 19391975, Alicante: Aguaclara.

Roldán, Mariano (1956), "Doce nuevos poetas”, Revista de la Facultad de Ciencias de la Educación de la Universidad de Antioquia, Medellín, 124, enero-marzo, 119-140

Sánchez Dueñas, Blas (2013), "Voces poéticas de mujer en la órbita de las antologías conformadoras de la generación del 50", Desde las orillas. Poetas del 50 en los márgenes del canon, ed. de María Payeras Grau, Sevilla: Renacimiento, pp. 229-250.

Valente, José Ángel (1955), “Once poetas”, Índice, n. 79, abril.

Vidal, Ma Antonia (1943), Cien años de poesía femenina española e hispanoamericana, Barcelona: Olimpo. 